\title{
AS POTENCIALIDADES DA TECNOLOGIA MÓVEL WHATSAPP PARA AVALIAÇÃO DA APRENDIZAGEM EM UM CURSO DE FORMAÇÃO DE PROFESSORES
}

\author{
Márcia Aparecida Silva ${ }^{1}$
}

Resumo: Neste artigo, busco investigar como ocorre a integração de tecnologias móveis para avaliar a aprendizagem, na formação inicial de alunos de um curso de Letras licenciatura português e inglês. Para realizar a pesquisa, embasei-me em Warschauer (2007), Prensky (2010), Kukulska-Hulme (2015) e Costa (2013), para discutir tecnologia digitais e formação docente; sobre avaliação da aprendizagem embasei-me em Taras (2007, 2009), Abedi (2010), Wiliam (2010), dentre outros. Esta é uma pesquisa qualitativa em que investiguei meu próprio contexto de trabalho, como professora formadora no curso de Letras, em uma disciplina de língua inglesa. Os dados foram coletados durante as aulas, por meio de discussões e análise de avaliações construídas pelos participantes. Os resultados desta pesquisa revelam a necessidade de os alunos terem contato tanto com teorias quanto com atividades práticas, como a construção de uma avaliação, para que aprendam a lidar com esses temas, dado que são futuros professores.

Palavras-chave: Tecnologias Móveis; Avaliação da Aprendizagem; Formação Docente.

\section{The potential of WhatsApp mobile technology to assess learning in a teacher training course}

\begin{abstract}
In this research, I aim at investigating how the integration of mobile technologies to assess learning occurs in the teachers training Letras course of Portuguese and English. To conduct the research, I based on Warschauer (2007), Prensky (2010) and Kukulska-Hulme (2015) to discuss digital technology and teacher training; to discuss learning assessment I based on Taras (2007, 2009), Abedi (2010), Wiliam (2010), among others. This is a qualitative research in which I investigated my own context, as a teacher training professor, in an English language learning course. The data were colleted during the classes by discussions and analisis of the assessments made by the participants The results of this research show the students' need to have contact with both theories and practical activities, such as assessment building, to learn how to deal with these themes in their future roles as teachers.
\end{abstract}

Keywords: Mobile Technologies; Learning Assessment; Teacher Training.

\footnotetext{
'Universidade Estadual de Goias.(marciasilva@ueg.br)
} 


\section{INTRODUÇÃO}

As pesquisas em torno da inserção de tecnologias digitais e móveis em sala de aula têm aumentado nos últimos tempos no âmbito da Linguística Aplicada (LIMA, 2012; COSTA, 2013; MORAN, 2015; KUKULSKA-HULME, 2015), com o objetivo de buscar meios de refletir sobre essa forma de ensinar, que demanda posicionamentos outros, tanto do professor, quanto dos alunos. Em uma sociedade cada vez mais digital há uma demanda para que o ensino se torne mais digital também, ou seja, que permita aos alunos relacionarem o que estão aprendendo em sala com suas vidas fora dela.

Entretanto, apesar de essas pesquisas e de vários professores se interessarem por um ensino relacionado ao uso de tecnologias digitais, percebo que, no contexto escolar, em alguns casos, o uso da tecnologia cumpre meramente um papel à margem do processo de ensino e de aprendizagem nas aulas. Esse uso parece não oportunizar uma articulação pedagógica mais produtiva para a relação do aluno com o conhecimento, algo do processo de ensino e de aprendizagem. Tal fato pôde ser percebido em meu contexto de trabalho em que as tecnologias eram por vezes utilizadas de forma conteudista, sem reflexão; daí meu interesse em pesquisar essa temática.

A partir de conversas informais com professores que usam tecnologias em suas aulas, notei que, em alguns casos, a tecnologia é usada para cumprir dado tempo de aula, como usar datashow, notebook, internet, aparelho de DVD para passar um filme de cinquenta minutos ou levar os alunos para o laboratório e deixá-los utilizar a internet sem um planejamento adequado. Todos esses fatos parecem gerar certa descrença em relação às tecnologias digitais, como se fosse de relevância secundária para o processo de ensino e também de aprendizagem.

Nessa perspectiva, a utilização das tecnologias digitais e móveis ainda não ganhou, no espaço escolar, um uso adequado, no sentido de uma integração do processo de ensino-avaliação-aprendizagem às tecnologias digitais, levando em consideração que elas têm muito a oferecer. Em uma entrevista sobre o tema, Prensky (2010) ressalta que usar tecnologias apenas como suporte para as aulas expositivas é um erro e pode não trazer benefício para o processo de aprendizagem dos alunos. Para que "a tecnologia tenha efeito positivo no aprendizado, os professores precisam primeiro mudar o jeito de dar aula” (PRENSKY, 2010, s/p). 
Nessa linha de pensamento, neste artigo, que é uma versão reformulada e atualizada de minha tese de doutorado (SILVA, 2018), objetivei compreender as potencialidades de tecnologias digitais, especificamente a tecnologia móvel WhatsApp, para a avaliação da aprendizagem em um curso de formação inicial de Letras português-inglês licenciatura, assim como as percepções de alunos sobre essa estratégia, de uma cidade do interior do estado de Goiás.

A pesquisa aconteceu em uma disciplina de língua inglesa, na qual, como professora, inseri reflexões e atividades práticas sobre tecnologias digitais e avaliação da aprendizagem durante o curso. Os dados foram coletados a partir de discussões em sala de aula sobre o uso do WhatsApp como ferramenta avaliativa, assim como analisei as avaliações produzidas pelos alunos. Passo, agora, à apresentação da teoria que embasa este artigo.

\section{ARCABOUÇO TEÓRICO}

Nesta seção, abordo teorias que envolvem a integração de tecnologias móveis ao processo de ensino-avaliação-aprendizagem de línguas. Segundo Prensky (2010), quanto mais vemos os alunos como seres individuais, com paixões e objetivos singulares, mais seremos capazes de atingir a todos os alunos. Isso porque o professor estabelece uma relação com eles, trabalhando juntos e permitindo que eles tenham um papel ativo no processo de ensino-avaliaçãoaprendizagem.

Os pesquisadores Ren, Warschauer, Lind e Jennewine (2009) apontam que os professores brasileiros possuem uma atitude positiva com relação à integração de tecnologias digitais na aprendizagem de línguas. A pesquisa revela que os professores brasileiros pesquisados, oriundos da rede pública, privada e ensino superior, buscam tanto recursos digitais quanto programas de computador que colaborem para as aulas, tornando-as mais atraentes e mais próximas da realidade dos alunos. Os autores finalizam argumentando que, por esse uso, os professores brasileiros deveriam ter mais voz no campo de pesquisas internacionais no âmbito de aprendizagem de línguas estrangeiras.

Sobre as possibilidades de integração de tecnologias digitais em ambiente presencial de sala de aula, Moran (2015, p. 39) argumenta que

Essa mescla entre sala de aula e ambientes virtuais é fundamental para abrir a escola para o mundo e também trazer o mundo para dentro da instituição. Outra mescla ou blended é aquela entre processos de comunicação mais planejados, organizados e formais 
e outros mais abertos, como os que acontecem nas redes sociais, em que há uma linguagem mais familiar, maior espontaneidade e fluência constante de imagens, ideias e vídeos.

As redes sociais podem ser compreendidas como espaços online em que as pessoas interagem umas com as outras e compartilham momentos, histórias, posicionamentos etc. Recuero (2016, p. 17) afirma que as redes sociais são espaços públicos em que os "discursos emergem, se difundem e são legitimados”. A autora lembra que esse espaço é híbrido, dado que permite a inserção de várias tecnologias digitais, e que permite que as interações fiquem armazenadas.

Relacionar as redes sociais à aprendizagem de línguas implica compreender que o ensino não é linear, como o proposto no ambiente escolar em que há uma tentativa de linearidade do processo. A não linearidade do ensino pode ser vista no fato de que o conhecimento pode ser produzido de maneira informal também. Isso porque o aluno sistematiza o conhecimento que lhe é pertinente para aquele momento específico de comunicação ou atividade, o que pode ir além daquele proposto pelo professor em sala de aula.

Nessa perspectiva, há várias pesquisas que demonstram que a educação formal não é a única fonte que o professor tem a seu dispor, como a pesquisa de Fiuza (2013), realizada com professores sobre seu processo de formação, que revela que não é possível separar a educação formal da informal. As análises da autora mostram que a linha entre ambos é tênue e que o conhecimento é construído a todo momento, não apenas na escola, ambiente considerado formal. Segundo Fiuza (2013, p. 100) "as experiências que formam um professor não se restringem somente àquelas vividas na academia, mas incluem também todas as outras vividas ao longo de sua vida”.

Assim, os alunos têm uma infinidade de opções de aprendizagem por meio das tecnologias digitais fora da escola, tais como as redes sociais com grupos sobre temas afins, comunidades de aprendizagem (RECUERO, 2016). Siemens (2004) possui posicionamento parecido com o de Recuero (2016) e o de Fiuza (2013) ao afirmar que a aprendizagem informal também é relevante para o processo de aprendizagem. Nessa medida, o ensino de línguas não se limita ao espaço de sala de aula. Há várias tecnologias digitais e redes sociais que estimulam a aprendizagem, tais como o Facebook, o Instagram, o Tik Tok e o WhatsAppque têm um papel relevante no processo de aprendizagem informal. 
Sobre o processo de ensino e aprendizagem de línguas mediado por tecnologias digitais, Kukulska-Hulme (2015, p. 287) argumenta que "as mídias digitais e móveis estão mudando o uso da linguagem ao mesmo tempo em que são um meio para estender o uso e o alcance de aprendizagem para qualquer língua”. Dessa maneira, é necessária uma adequação a essa nova forma de aprender, de lidar com o processo de ensino-avaliação- aprendizagem de línguas.

Há estudos que investigam a integração de tecnologias móveis para a aprendizagem de línguas, como a dissertação de Gomes (2015) que pesquisou a integração de dispositivos móveis na aprendizagem da língua inglesa de alunos de um instituto de idiomas de uma universidade federal. Os resultados da pesquisadora revelam que, apesar de os alunos utilizarem tecnologias móveis o tempo todo, eles ainda não estão acostumados a ver esse tipo de tecnologia como aliada do processo de aprendizagem. Isso porque os alunos ainda veem a tecnologia digital em sala de aula como algo tradicional; dessa forma, eles, todavia, não conseguem se apropriar das possibilidades da tecnologia móvel para aprender línguas de forma autônoma.

A pesquisa que resultou no artigo de Braga e Silva (2017) ocorreu em um curso online de extensão para professores em formação. A plataforma utilizada foi o WhatsApp; por meio das análises, foi possível perceber que os futuros professores aprovaram o uso da tecnologia móvel para aprender e, em sua maioria, disseram que utilizariam essa tecnologia em suas aulas, quando se tornassem professores em exercício. Além disso, as análises revelam a necessidade de se inserir discussões sobre as possibilidades das tecnologias móveis em cursos de formação de professores, para que esses futuros profissionais possam refletir sobre seus limites e suas vantagens.

Seguindo a linha de investigação de Braga e Silva (2017), a pesquisa de Santos, Pereira e Mercado (2016) também ressalta a necessidade de discutir sobre tecnologias móveis em cursos de formação docente. Os autores afirmam que é preciso preparar tais professores para um ambiente educacional que está mudando, com alunos que demandam outros posicionamentos e atitudes.

As tecnologias móveis têm muito a contribuir com o processo de ensinoavaliação-aprendizagem de línguas; isso porque integra algo do cotidiano da maioria dos alunos à aprendizagem. Acredito que tais tecnologias aprofundam os aspectos colaborativos, comunicativos e sociais da língua e, além disso, também 
"[...] permitem uma aprendizagem que é situada e contextualizada” (PEGRUM; HOWITT; STRIEPE, 2013, p. 464). Para Kukulska-Hulme (2015, p. 282),

[a] aprendizagem móvel pode fornecer, complementar e ampliar a aprendizagem formal de línguas; ou ela pode ser o primeiro passo para os alunos explorarem a língua informalmente e direcionar seu próprio desenvolvimento por meio de desafios imediatos encontrados no ambiente virtual.

Por meio da citação posso afirmar que o processo de ensino-avaliaçãoaprendizagem de línguas integrado ao uso de tecnologias móveis pode colaborar para que os alunos se tornem mais independentes em sua aprendizagem, além de possibilitar um ensino mais próximo à sua realidade.

Além de pesquisas que enfatizam a integração de tecnologias móveis em sala de aula, há outras que enfocam a inserção de tecnologias digitais no ensino de habilidades específicas, como o texto de Faria (2016), que apresenta pontos relevantes no que se refere à integração de gêneros digitais orais em sala de aula presencial, para aprimorar a habilidade oral dos alunos. A autora propôs oito tarefas para os alunos que incluiriam algum tipo de tecnologia digital. Ao discutir seus resultados, Faria (2016) considera que um dos pontos positivos foi a interação entre os alunos ao realizarem as atividades propostas por ela. Além disso, houve uma melhora significativa na habilidade oral da turma ao final das atividades. O trabalho de Faria (2016) me é relevante ao mostrar que a integração de tecnologias digitais para ensinar e aprender línguas já é uma realidade que funciona em alguns contextos; seus alunos aprovaram a ideia e se sentiram mais motivados para aprenderem.

O trabalho de Gomes (2015) investigou um curso de formação docente, no que se refere ao gênero exposição oral, tomando por base as teorias dos multiletramentos. Os resultados da pesquisa revelam que os professores ainda desconhecem os recursos digitais que podem colaborar para o desenvolvimento da habilidade oral de língua inglesa. O curso de formação foi relevante para esses educadores porque propiciou um conhecimento dos recursos e uma reflexão sobre seus usos em ambiente escolar. Por meio de seus resultados, Gomes (2015) ressalta a necessidade de se inserir discussões acerca das tecnologias digitais em contexto de formação inicial. Acredito que, quando os futuros professores aprendem a usar e a refletir sobre as tecnologias digitais disponíveis, eles podem ficar mais seguros em usá-las, quando forem para a sala de aula. Em sua pesquisa, Warschauer (2007, p. 48) enfatiza a relevância do papel do professor no ensino 
tecnológico de línguas afirmando que "as novas tecnologias não substituem a necessidade de uma orientação humana forte, mas, de fato, amplifica o papel de tal orientação".

Sobre a questão da formação de professores, Bohn (2013) utiliza o termo uniformizada para se referir ao modelo de escola pelo qual passamos e pelo qual a geração atual também está passando. Um modelo de educação que engessa, modela e que visa à uniformização do ensino, dificulta que o professor em formação reflita sobre suas práticas pedagógicas e, ainda, resista a repensá-las. Essa uniformização tende a alienar os professores que ainda estão se formando.

Além disso, Bohn (2013) problematiza uma outra dificuldade - ou resistência - relacionada aos professores com o uso das tecnologias digitais em sala de aula presencial. Constituído em um contexto de aprendizagem tradicionalista, em que o uso de tecnologias se restringia a livros e quadro negro, dificilmente o professor em serviço usaria ferramentas tecnológicas para ensinar. Por essa razão, considero necessário inserir discussões sobre essa temática em curso de formação de professores, para que os futuros professores se familiarizem com as ferramentas e saibam em que momento inseri-las em seus cotidianos.

Além de Warschauer (2007), Prensky (2010) também discute sobre o papel do professor e o uso de tecnologia digital nas aulas presenciais. Segundo Prensky (2010), o professor precisa se inserir nesse modelo de educação que se configura mais e mais digital e compreender que há a necessidade de buscar outras formas para ensinar, usando a criatividade para se adaptar a um contexto em que os alunos utilizam tecnologias digitais em seus cotidianos. Isso porque as formas atuais não conseguem abarcar a complexidade que é ensinar utilizando ferramentas digitais, dado que são formas que demandam um ensino presencial, com o professor controlando o processo.

Entretanto, Prensky (2010, p. 100) ressalta que o professor não tem de conhecer as tecnologias digitais a fundo, ele é o "guia, o instrutor, e o controlador da qualidade, não o usuário das tecnologias”. O papel de usuário é dos alunos, são eles que devem aprender a usar a tecnologia para realizar as atividades propostas. Para o autor, professores fluentes tecnologicamente tendem a usar a tecnologia para os alunos, seja criando contas nas ferramentas digitais, seja facilitando o processo. Isso faz com que eles não desenvolvam todo o seu potencial. 
Sobre o papel que os professores devem assumir frente a integração das tecnologias digitais no sistema de ensino, Warschauer (2011) pontua que eles têm uma relevante função, a de reconstruir o processo de ensino, usufruindo das possibilidades que as tecnologias digitais oferecem para preparar os alunos para um mundo em constante mudança.

Um modo de repensar o processo de aprendizagem, segundo Prensky (2010), é criar novas metodologias para se ensinar. Contudo, o autor observa que os professores devem permitir que os alunos participem desse processo, uma vez que essa participação pode conscientizar os alunos de seus papéis no processo de aprendizagem, além de ajudá-los a se tornarem independentes. Uma forma de permitir essa participação é "dar aos alunos questões para pesquisar, explorar e encontrar soluções e levá-las para sala de aula para discutir e analisar" (PRENSKY, 2010, p. 15). Além disso, Prensky (2010) defende que a parceria enfatiza os papéis dos alunos e do professor como igualmente relevantes e que cada um deve se esforçar para melhorar o processo de aprendizagem como um todo.

A integração de tecnologias digitais para o processo de ensino-avaliaçãoaprendizagem ainda tem muitos desafios pela frente. Warschauer (2011) atenta para o fato de que a tecnologia digital não é resposta para os problemas enfrentados em sala de aula. O autor afirma que "assim como a música não reside no piano, ensino, aprendizagem e conhecimento não residem no computador" (WARSCHAUER, 2011, p. 05).

O posicionamento de Warschauer (2011) é relevante na medida em que desconstrói o senso comum que geralmente ouvimos de que a tecnologia veio para salvar a educação. Em seu livro, o autor mobiliza vários exemplos de histórias reais para mostrar que, se for inserida sem reflexão, a tecnologia digital fracassa em seu propósito, que é se incorporar as vivencias educacionais e colaborar para com o processo de ensino-avaliação-aprendizagem.

Refletindo sobre a questão da avaliação da aprendizagem, neste artigo compreendo o conceito com base em Taras (2007, 2009), Abedi (2010) e Cizek (2010), que discutem os modelos de avaliação como imbricados e relacionados, e, também, a relevância de uma avaliação cujo interesse não seja medição de notas, mas sim, observar e colaborar para com a aprendizagem do aluno. Nessa perspectiva, a avaliação aqui e compreendida como "uma fonte de informação que os professores podem usar no planejamento instrucional e os alunos podem 
usá-la para aprofundar seus conhecimentos e aprofundar resultados” (CIZEK, 2010, p. 07).

Nessa seção, meu intuito foi apresentar ao leitor pesquisas sobre a integração de tecnologias digitais no processo de ensino-avaliação-aprendizagem de línguas, além de apresentar teóricos relevantes para a área de pesquisa.

Na próxima seção, abordo o escopo metodológico da pesquisa.

\section{METODOLOGIA}

Esta é uma pesquisa qualitativa, nos termos de Denzin e Lincoln (2006), no qual os autores afirmam que esse modelo de pesquisa não se refere a um campo específico, os atravessa, estando presente em quase todos os campos das ciências humanas. Como o termo pesquisa qualitativa é um termo guarda-chuva (ANDRÉ, 2008), optei por um estudo de caso por esta ser uma pesquisa em um contexto específico, uma sala de aula de língua inglesa, na qual, eu como professora, investiguei as potencialidades do Whats $A p p$ para avaliar a aprendizagem.

A pesquisa aconteceu em uma universidade pública do interior do Estado de Goiás, no ano de 2017. Especificamente, a pesquisa foi realizada em uma disciplina do curso de Letras, que oferece dupla licenciatura em Português e em Inglês. Assim, a coleta de dados ocorreu na disciplina de Língua Inglesa V, na qual eu, como professora, inseri discussões sobre avaliação da aprendizagem nas aulas e também solicitei que os alunos criassem avaliações por meio de tecnologias digitais para avaliar a aprendizagem dos colegas. $\mathrm{O}$ intuito era que eles experienciassem o que é ser professor e como é criar uma avaliação. Dessa forma, os alunos da disciplina se reuniram em grupos, selecionaram ferramentas tecnológicas e prepararam avaliações para os colegas.

Para esta pesquisa, selecionei uma ferramenta específica, a saber, WhatsApp. Como os professores em formação não têm disciplinas que enfatizem a formação docente em disciplinas específicas, considerei relevante inserir nas aulas de língua inglesa, discussões e atividades que proporcionassem aos professores em formação reflexões sobre como usar tecnologias digitais para avaliar a aprendizagem. Ressalto que a pesquisa ocorreu, assim como a coleta de dados, após a aprovação do comitê de ética na pesquisa. 
Com isso, os dados, neste trabalho, compõem-se atividades em sala e com a tecnologia móvel WhatsApp, além de alguns trechos de discussões gravadas com a turma. Dessa forma, conforme explicado, os alunos da disciplina formaram pequenos grupos e prepararam atividades avaliativas, utilizando o Whats App, para os colegas em sala. A proposta foi que o grupo deveria: construir avaliações e critérios, ministrar tais avaliações aos colegas e, depois, corrigi-las seguindo critérios previamente estipulados pelo grupo com meu auxílio. O intuito foi pensar a formação docente com atividades práticas, refletindo sobre a construção de avaliação usando tecnologia móvel e, depois, criar e usar os critérios criados para avaliar os colegas. Depois de todo o processo, nos reunimos e discutimos as dificuldades, os pontos positivos e os negativos.

Passo, neste momento, para as análises da pesquisa.

\section{ANÁLISES}

A tecnologia digital selecionada para esta pesquisa foi o WhatsApp. Os participantes da disciplina que se reuniram em grupo para realizar a atividade são: Nasus, Evelyn e Deby ${ }^{2}$. Esse grupo teve alguns atritos para escolher as atividades que iriam postar na plataforma, e, depois, para fornecer as notas para os colegas; todos esses problemas foram relevantes para a constituição dos participantes desta pesquisa como futuros professores.

Além do uso social, o WhatsApp é um aplicativo que pode colaborar bastante para o processo de ensino-avaliação-aprendizagem de línguas estrangeiras. Ele permite a inserção de diversas atividades, e também links que direcionam o usuário para outros espaços. É possível trabalhar as quatro habilidades da língua: ouvir, falar, ler e escrever, e criar grupos com interesses em comum, grupos de alunos. Ademais, como é algo muito comum na atualidade, dado que quase todas as pessoas que usam dispositivo móvel possuem o aplicativo, parece haver uma aceitação maior por parte dos alunos.

A seguir, segue uma imagem da primeira instrução das atividades propostas pelo grupo:

2 Todos os nomes são fictícios e foram escolhidos pelos participantes. 
Figura 1: Avaliação com WhatsApp

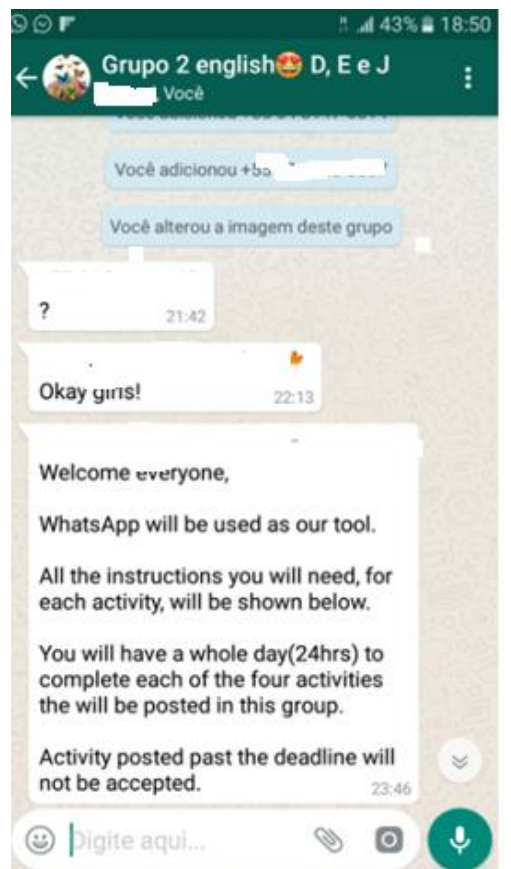

Fonte: arquivo pessoal da pesquisadora

Além do uso social, o WhatsApp é um aplicativo que pode colaborar bastante para o processo de ensino-avaliação-aprendizagem de línguas estrangeiras. Ele permite a inserção de diversas atividades, e também links que direcionam o usuário para outros espaços. É possível trabalhar as quatro habilidades da língua: ouvir, falar, ler e escrever, e criar grupos com interesses em comum, grupos de alunos. Ademais, como é algo muito comum na atualidade, dado que quase todas as pessoas que usam dispositivo móvel possuem o aplicativo, parece haver uma aceitação maior por parte dos alunos. Segundo Souza; Martins; Racilan (2012, p. 196),

3 Tradução da figura 1: Olá, meninas; sejam bem vindas, WhatsApp será usado como nossa ferramenta. Toda as instruções que vocês irão precisar, para cada atividade, serão mostradas abaixo. Vocês terão um dia inteiro (24h) para completar cada uma das quatro atividades que serão postadas aqui no grupo. Atividade postada após o prazo final não será aceita. 
o uso da tecnologia não só é capaz de proporcionar ao professor um acompanhamento regular do progresso de todos os alunos. Mas ainda de permitir que eles acompanhem o trabalho e o desenvolvimento de seus colegas.

Esse acompanhamento pode ser por meio de várias opções, os autores mencionam algumas como interações online. Na plataforma WhatsApp, por exemplo, todos podem ver as atividades de todos, o que colabora para as práticas pedagógicas do processo de ensino-avaliação-aprendizagem de línguas.

A princípio, o grupo teve dificuldade em escolher a forma de avaliação utilizando o aplicativo. Evelyn sugeriu várias atividades em que havia apenas transposição do impresso para o digital, com atividades mecânicas de repetição, tais como construir a mesma frase: interrogativa, negativa e afirmativa, para praticar dado tempo verbal, sem nenhum contexto. Os colegas queriam outras atividades, de modo que o grupo não estava conseguindo se entender e chegar a um consenso.

Para ajudá-los, me reuni com o grupo e conversamos sobre como eles queriam avaliar, expliquei que, avaliar em contexto digital, demandava outra postura, outros tipos de atividades, se fosse para ser igual ao presencial, por que usar tecnologia? Com isso, eles discutiram e decidiram pedir quatro atividades no aplicativo, todas em língua inglesa: 1) tirar uma foto em tempo real e descrever a foto, em áudio, assim como a atividade daquele momento - o foco gramatical foi no uso do presente simples e vocabulário de atividades cotidianas; 2) enviar uma foto de algum lugar ou pessoa que seja importante e escrever uma postagem sobre ela - foco na escrita e vocabulário relacionado a sentimentos; 3) buscar a língua inglesa no cotidiano, em anúncios, placas na rua etc, e formular uma frase com aquela palavra - foco na escrita e processo de aculturação; 4) a última atividade era uma resposta à pergunta: em que medida você apoia o uso de tecnologias digitais no ensino da língua inglesa? - foco na capacidade de escrita e de argumentação, pois deveriam responder e interagir com os colegas. Destaco que os critérios de avaliação se relacionaram com as atividades e tiveram, a princípio, foco nas estruturas gramaticais e na pronúncia. Segundo Deby, a escolha por esse aplicativo ocorreu porque

todo mundo conhece, todo mundo tá todo dia usando a ferramenta que queremos utilizar, então, vamos optar por uma ferramenta mais fácil. Nós pensamos em vocês ((risos de todos)), mas é sério ((Deby disse rindo)) (DEBY, discussão em sala sobre a escolha do aplicativo). 
É possível observar a representação de Deby de que a facilidade de uma tecnologia digital está no uso regular das pessoas. Essa representação remete ao conceito de normalização de Bax (2011, p. 02), quando o autor pontua que "a tecnologia alcançará sua eficácia completa no ensino de línguas quando chegar ao estágio denominado de normalização". Acredito que a tecnologia móvel já seja algo normalizado na vida social das pessoas, mas não como instrumento de avaliação. Entretanto, a partir da normalização do uso social, parece fazer sentido Deby pensar no aplicativo como um suporte pedagógico.

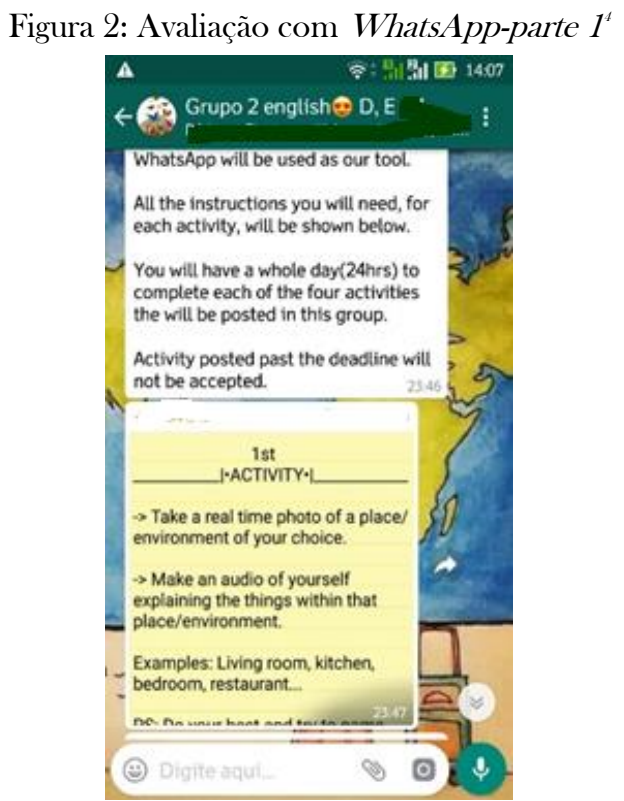

Fonte: arquivo pessoal da pesquisadora

Os futuros professores gostaram de fazer as atividades; alguns, mais tímidos, reclamaram por ter que gravar um áudio. Segundo eles, como não se consideram fluentes, esse tipo de atividade é um desafio. Como professora da turma eu

4 Tradução da figura 2: WhatsApp será usado como nossa ferramenta. Toda as instruções que vocês irão precisar, para cada atividade, serão mostradas abaixo. Vocês terão um dia inteiro (24h) para completar cada uma das quatro atividades que serão postadas aqui no grupo. Atividade postada após o prazo final não será aceita. Primeira atividade: tire uma foto em tempo real de um lugar, ambiente de sua escolha. Faça um áudio explicando os objetos dentro do lugar/ambiente. Exemplo: sala de estar, cozinha, quarto, restaurante.. 
deveria ter proposto uma atividade escrita antes ou mesmo sugerido que o grupo que criou a avaliação propusesse, como isso não foi feito, houve dificuldade de alguns participantes. Na figura 3, a seguir, vemos a postagem de Luana. Além de uma foto sua, em casa, e um áudio, Luana produziu uma um texto escrevendo as palavras novas que aprendeu para realizar a atividade.

É possível observar que houve interação entre as alunas Luana e Ninária. Apesar de não ter interagido muito, Ninária ouviu todos os áudios e comentou alguns em que se sentiu mais à vontade. Essa interação no aplicativo mostra que os futuros professores aprendem a língua-alvo de forma contextualizada quando não se sentem pressionados. Segundo Braga e Silva (2017) ambientes virtuais promovem uma maior interação entre os alunos, eles parecem ser sentir mais confiantes e, em razão disso, interagem mais. A aprendizagem ocorre de maneira colaborativa, em que eles buscam as palavras que precisam para construir as postagens e, como Luana, pedem ajuda para corrigir os possíveis erros.

Figura 3: Avaliação com WhatsApp-interações ${ }^{5}$

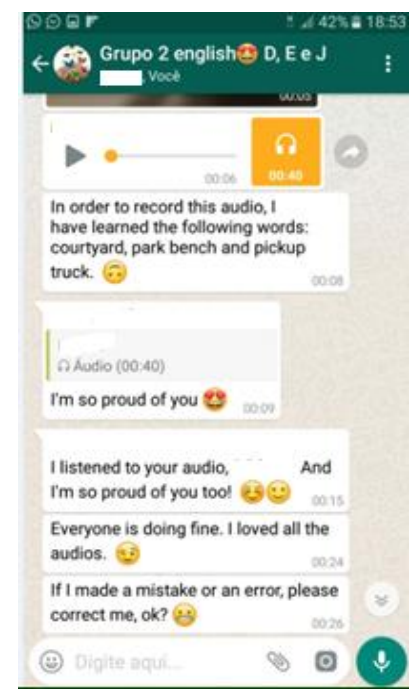

Fonte: arquivo pessoal da pesquisadora

5 Tradução da figura 3 :

Luana: para gravar esse áudio, eu aprendi as seguintes palavras: pátio, banco de praça, camionete.

Ninária: eu estou tão orgulhosa de você.

Luana: eu ouvi o seu áudio, e estou orgulhosa de você também. Todos estão indo bem. Eu amei todos os áudios, se eu cometer um equívoco ou um erro, por favor, me corrijam, ta bom? 
$\mathrm{Na}$ segunda atividade, eles escolheram falar sobre um lugar para onde viajaram e de que gostaram muito; assim, postaram uma foto e escreveram o porquê aquele lugar era importante. A maioria dos participantes utilizou um tom sentimental quando foi descrever o lugar escolhido. Ainda que esse tipo de atividade não demande uso de tecnologia, podendo ter sido feito em sala de aula, foi significativo para o grupo que a propôs. Na figura 4, é possível ver o tom melancólico que Luana utiliza para escrever sua postagem, relembrando sua infância. Na figura 5 , vemos os colegas interagindo e comentando as postagens de Luana e de Julia.

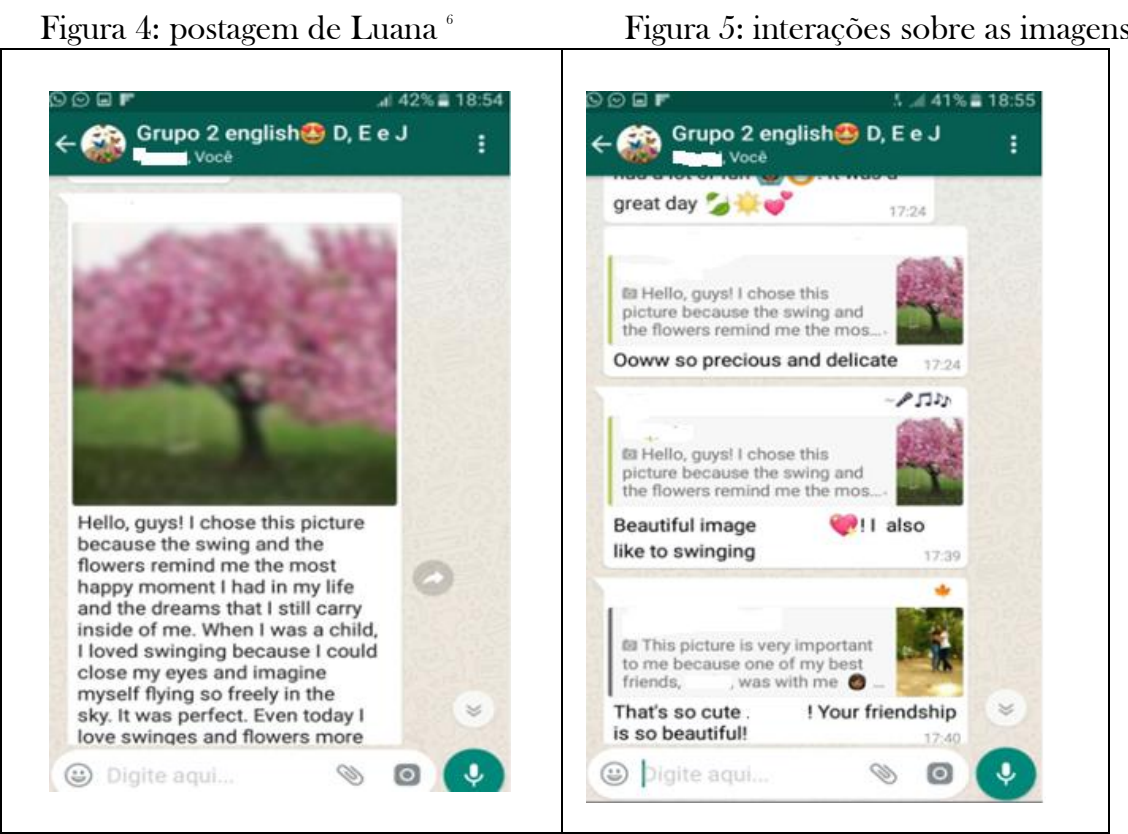

Fonte: arquivo pessoal da pesquisadora

\footnotetext{
${ }^{6}$ Tradução da figura 4:

${ }^{7}$ Tradução da figura 5:

Ninária: ohhh, tão precioso e delicado;

Wonder woman: bela imagem, eu também gosto de balançar;

Julia: que fofo, sua amizade é tão bonita.
}

Luana: Olá, pessoal. Eu escolhi essa foto porque o balanço e as flores me lembram do momento mais feliz da minha vida e dos sonhos que carrego dentro de mim. Quando eu era criança, eu adorava balançar porque eu podia fechar meus olhos e me imaginar voando livremente no céu. Ainda hoje eu amo balanços e flores.. 
Um ponto que foi discutido em sala de aula foi o fato de quase todos interagirem entre si nas atividades, utilizando a língua-alvo, como é possível ver na figura 5. Isso não foi demandado pelo grupo. A pesquisa de Braga e Silva (2017) demonstra que, em ambientes virtuais, pode haver maior interação entre os alunos; dentre as razões destacadas pelas autoras está o fato de os alunos se sentirem mais seguros. Nesta pesquisa, o mesmo parece acontecer com os participantes, pois, quando os alunos estão em um ambiente que lhes transmite confiança, a aprendizagem parece acontecer de maneira mais segura, o que pode ser observado na figura 5. Apesar de estarem sendo avaliados, eles quiseram ir além do que foi pedido, porque o aplicativo tem essa função social, de interação.

Nesse sentido, concordo com Kukulska-Hulme (2015, p. 285) quando a autora afirma que "a aprendizagem móvel não é apenas um meio de aprender uma língua; ela é também uma lente na qual é possível ver a língua em uso e um instrumento que pode mudar esse uso". Nessa perspectiva, o aplicativo WhatsApp possibilita muito mais que o ensino da língua em si mesmo; nesta pesquisa, os participantes, aparentemente, esqueceram-se que estavam sendo avaliados e utilizaram a tecnologia móvel para interagir, como fariam se estivessem usando o aplicativo para fins sociais e informais, contudo, tendo a língua inglesa como suporte.

A terceira atividade foi uma espécie de desafio: encontrar a língua inglesa em lugares diversos, como nome de lojas, roupas, produtos e, depois, construir uma frase com o nome escolhido. É possível notar que, após sua postagem de resposta, Julia pede ajuda na construção da frase, o que pode ser compreendido como uma aprendizagem colaborativa, ela não especificou a mim como professora, ou ao grupo responsável; quando usa o substantivo guys, ela refere-se à sala toda, isso demonstra que a plataforma também descentraliza o papel do professor; nela, todos se ajudam e aprendem juntos, o que corrobora o que Prensky (2010) chama de aprendizagem participativa.

É possível notar que Julia utilizou emojis ${ }^{8}$ em sua resposta com o intuito de enfatizar o que está afirmando. De acordo com Paiva (2016, p. 396),

\footnotetext{
${ }^{8}$ Compreendo nessa pesquisa emöis como caracteres tipográficos que demonstram o sentimento daquele que os usa.
} 
o uso dos emojis é uma tentativa de transmitir mais sentido de forma mais econômica em determinados contextos de interação, mas, ao mesmo tempo, fazendo emergir sentidos acrescidos de muitos outros significados, especialmente, de emoções.

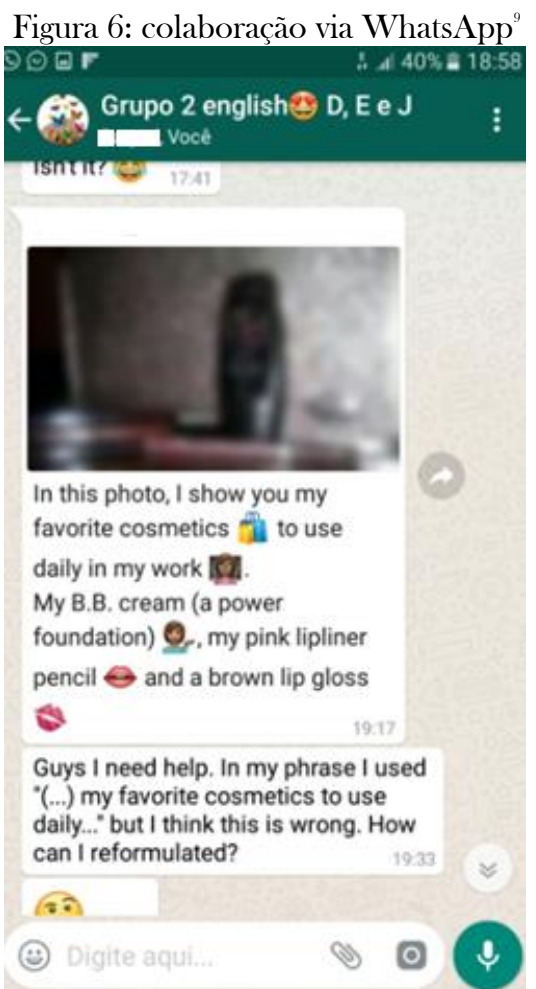

Fonte: arquivo pessoal da pesquisadora

Nesta pesquisa, notei que os futuros professores não utilizam os emoj̈s apenas como uma forma de economia de palavras, o uso mais recorrente está como uma forma de dar sentido, emoção às suas produções escritas, sejam elas formais, no momento de responder, sejam elas informais, no momento de

${ }^{9}$ Tradução da figura 6 :

Julia: nesta foto, eu mostro para vocês meus cosméticos favoritos para usar diariamente no meu trabalho. Meu creme B.B (uma fundação poderosa), meu lápis de boca rosa e meu gloss labial marrom. Pessoal, eu preciso de ajuda. Na minha frase eu usei “(...) meus cosméticos favoritos para usar diariamente...” mas eu acho que está errado, como eu posso reformular? 
interagir com os colegas. Pude notar que, quando os professores de formação inicial inseriram emojis em suas respostas, eles se sentiram mais à vontade com a avaliação, pois ela passou a fazer parte de algo que já estão habituados, dado que quase todas as redes sociais possuem a opção de emoj̈s.

A última atividade do grupo foi uma pergunta que poderia ser respondida via áudio ou mensagem. A pergunta era: qual sua opinião sobre avaliar usando tecnologias digitais?

Figura 7: atividade 4 do Whats $A p p^{10}$

\begin{tabular}{|c|}
\hline $29 / 05 / 2017-23: 59$ \\
\hline 13/02/18 10:34 AM \\
\hline 4th \\
\hline _ $|\cdot A C T I V I T Y \cdot|$ \\
\hline $\begin{array}{l}\text {-> Tell us your opinion about: } \\
\text { Education mixed with technology. }\end{array}$ \\
\hline $\begin{array}{l}\text {-> Do you support the use of tools } \\
\text { (WhatsApp, wizer.me, Google+ } \\
\text { and more) in Education? Are you } \\
\text { against it? }\end{array}$ \\
\hline $\begin{array}{l}->\text { What do you think that would } \\
\text { help the students to learn English? }\end{array}$ \\
\hline $\begin{array}{l}\text { PS: Make it a short answer. } \\
\text { (Thank God it's the last activity :')) }\end{array}$ \\
\hline *TEXT or AUDIO* \\
\hline$\triangleleft \quad \bigcirc \quad \square$ \\
\hline
\end{tabular}

Fonte: arquivo pessoal da pesquisadora

O que me chamou a atenção na atividade foi o comentário de Nasus, "graças a Deus essa é a última atividade". Esse comentário gerou riso na sala entre todos, mas que também demonstra que Nasus já estava cansado das atividades. Quando fomos discutir a avaliação do grupo, notei que Nasus não se referia ao grupo quando ia comentar a construção da avaliação, apenas a si mesmo, como é possível observar em: 1) "[..] porque eu queria realmente um vídeo”, 2) “[...] só que eu achei que iam, muitas pessoas iam ficar desinteressadas”, 3) “[...] eu quero

${ }^{10}$ Tradução da figura 7:

Grupo: quarta atividade: nos conte sua opinião sobre: educação mesclada com tecnologia. Você apoia o uso de ferramentas (WhatsApp, wizzer.me, google+ e outros) na educação? Você é contra? O que você acha que poderia ajudar os alunos a aprender inglês? p.s: faça uma resposta curta. (Graças a Deus essa é a última atividade (:) * TEXTO ou ÁUDIO. 
trabalhar”, e 4) “[...] eu tentei manter o nível médio, assim, eu não quis considerar atividades fáceis demais". O uso do pronome pessoal de primeira pessoa do singular, repetidas vezes, pode revelar que Nasus considerou ter construído a avaliação sozinho. Em sala de aula, quando mostrei as análises e discutimos, Nasus disse que foi apenas uma forma de se expressar, que ele considera que todo o grupo trabalhou junto. Dessa forma, o eu utilizado por Nasus representa todo seu grupo.

Nas figuras a seguir temos as respostas de Amélie e Luana para a questão 4. Não foram todos os participantes que responderam a essa questão. Evidenciamos que a reflexão que Amélie constrói em sua resposta: "eu sei que nosso trabalho talvez seja duro o início, mas vale a pena (I know that our work maybe it's going to be hard in the beginning but it's Worth)". O uso de modalizadores em sua fala, "but it's worth", revela que a futura professora sabe que a docência não é fácil e que terá dificuldades no caminho; contudo, isso não lhe tira o desejo de seguir, porque sabe que valerá a pena o esforço despendido.

Apesar de haver alguns erros na postagem de Amélie, é possível ver seu crescimento, ela consegue expressar seus argumentos com segurança. Pude perceber uma mudança no papel social tanto de Luana quanto de Amélie, de aluno para professor, quando elas emitem seus posicionamentos sobre a integração de tecnologias no processo de ensino-avaliação-aprendizagem.

Em sala de aula, discutimos a avaliação no aplicativo WhatsApp, assim como as possibilidades e os limites da ferramenta. Julia afirmou que "o WhatsApp é uma ferramenta instantânea, se você joga um vídeo no WhatsApp de mais de três minutos, por exemplo, ninguém nem vai assistir, porque no WhatsApp é tudo muito rápido". O comentário de Julia refere-se à dúvida de Nasus sobre inserir ou não um vídeo nas questões propostas pelo grupo.

Na discussão, todos disseram que não gostam de vídeos ou áudios longos, e que utilizar esse recurso na avaliação seria algo cansativo e que descaracterizaria o aplicativo. Penso que, como o WhatsApp é uma ferramenta de troca de mensagens instantânea, os futuros professores acreditam que todas as atividades inseridas nesse espaço precisam seguir o mesmo padrão, o que gerou a discussão e reflexão em sala em inserir vídeos mais longos nas avaliações. 
Figura 8: resposta de Amélie no WhatsA $p p$ Figura $^{11}$ 9: Resposta de Luana no WhatsApp ${ }^{22}$

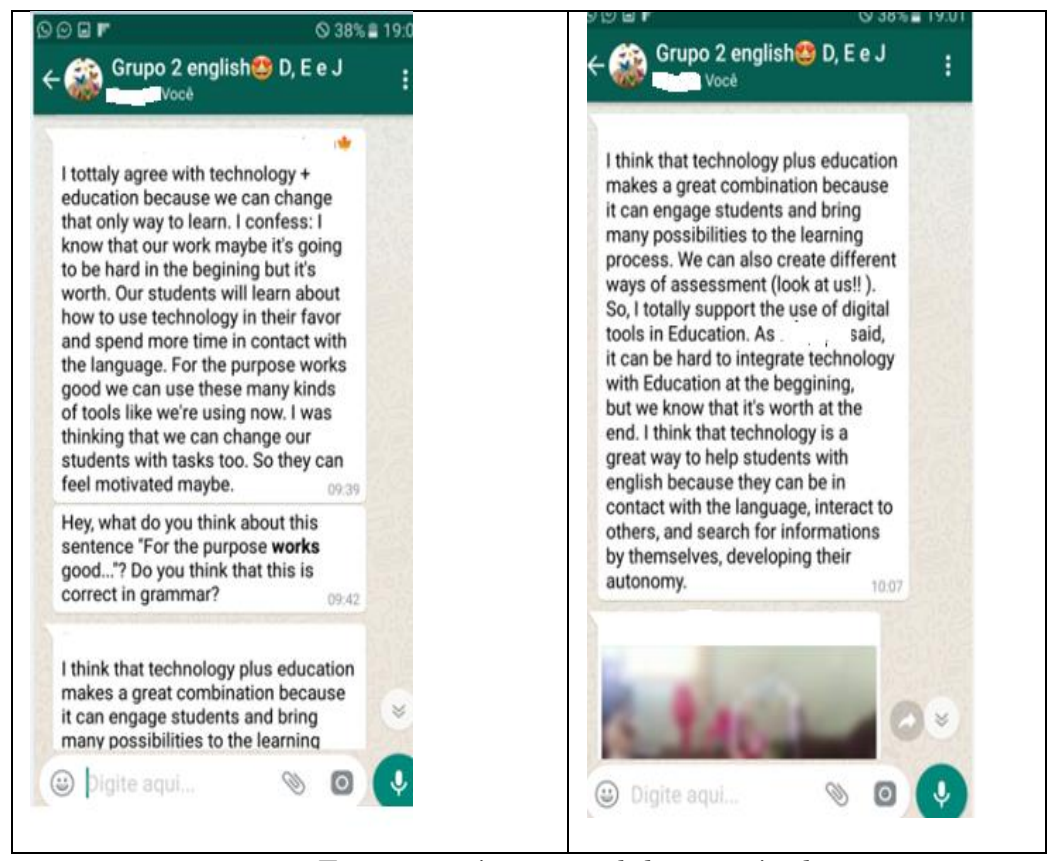

Fonte: arquivo pessoal da pesquisadora

A fala de Amélie é em torno da autonomia que o aplicativo propicia; destacamos que, quando vai dizer o que pensa, Amélie se posiciona em dois papéis: de aluna e de professora:

11 Tradução da figura 8:

Amélíe: eu concordo totalmente com tecnologia mais educação porque nós podemos mudar aquela única forma de aprender. Eu confesso: eu sei que nosso trabalho as vezes será difícil no início, mas vale a pena. Nossos alunos aprenderão a usar a tecnologia em seu favor e ter mais tempo de contato com a língua. Para esse proposito funciona bem usar essas ferramentas como as que estamos usando agora. Eu estava pensando que nós podemos mudar nossos alunos com tarefa também. Então talvez eles se sintam motivados. Hey, o que vocês acham dessa sentença “..para esse propósito funciona bem..” vocês acham que está correto gramaticalmente? 12 Tradução da figura 8:

Luana: eu acho que tecnologia e educação fazem uma ótima combinação, porque pode engajar os alunos e trazer muitas possibilidades para o processo de aprendizagem. Nos também podemos criar várias formas de avaliação (olhe para nós!) então, eu apoio totalmente o uso de tecnologias digitais na educação, como Amélie disse, pode ser difícil integrar tecnologia com educação no início, mas nós sabemos que valerá a pena no final. Eu acho que a tecnologia é uma ótima forma de ajudar nosso alunos com o inglês porque nós podemos estar em contato com a língua, interagir com outros, e buscar nós mesmos por informação, desenvolvendo autonomia. 
Eu acho que isso que a Julia falou em relação ao tempo é interessante porque a gente fala muito de jogar autonomia no aluno, e essa atitude, ah, você vai escolher o seu tempo, e pode ter um dia que você pode atrasar, então eu vou organizar a minha vida pra fazer, aí então dá mais autonomia pra mim, mais responsabilidade com os compromissos, com as tarefas e tal (AMÉLIE, discussão da avaliação com o WhatsApp).

Por meio dos modalizadores "eu acho que... é interessante", nos quais Amélie constrói sua opinião por meio de fatos observáveis, e dos modalizadores "pode ter um dia", "você vai ter o seu tempo", que se referem a valores sociais construídos. Para Amélie, o fato de o aluno poder realizar a atividade no momento que lhe for mais conveniente colabora em sua autonomia, dado que isso o responsabiliza sobre a tarefa a ser feita, ele vai saber que, se não a fizer, a consequência será dele.

Luana, por seu turno, apreciou o lado formativo do aplicativo, pois, segundo a futura professora

[o] Whats App, eu achei até interessante porque justamente ele é um dos que mais voltam para o lado formativo, igual as meninas falaram. O que mais gostei também foi a questão da interação porque logo que postaram os áudios, eu nem tinha feito os meus ainda, postaram, e eu já fui ouvir e fiquei achando interessante porque eu já fiquei olhando, dava pra ver que cada um que fez o áudio estava melhorando, a pronúncia, talvez, tinha alguns errinhos, mas dava pra ver que estava melhorando (LUANA, discussão da avaliação com o WhatsApp)

A partir do excerto de Luana, vemos que há uma relação do aplicativo WhatsApp com uma avaliação mais formativa, no sentido de que é possível aprender com a avaliação e observar o progresso dos alunos. Luana, ao ouvir os áudios dos colegas, conseguiu observar que houve uma melhoria na habilidade oral, habilidade essa que toda a sala julga ser a mais difícil de construir. O fato de o aluno ouvir o áudio do colega e perceber o que precisa ser melhorado faz com que ele também olhe e avalie sua própria pronúncia.

O WhatsAppé um aplicativo que, de fato, pode colaborar para o processo de ensino-avaliação-aprendizagem. Nesta pesquisa, os futuros professores gostaram muito de utilizar a ferramenta; na conversa que tivemos ficou evidente que a interação no momento de realizar as atividades avaliativas possibilitou que eles ficassem mais calmos, tirando, assim, o estresse que envolve as avaliações. 
Esse aspecto informal que o aplicativo oferece é, portanto, um aliado do professor, o que me remete a Kukulska-Hulme (2015, p. 282), quando a autora afirma que a "aprendizagem móvel pode fornecer, complementar e ampliar a aprendizagem formal de línguas”. Dessa forma, levando algo que os participantes já utilizam cotidianamente, o grupo conseguiu avaliar a aprendizagem e possibilitar a construção de conhecimento.

Além da interação, pude notar também que os participantes aprenderam de forma participativa, pediam ajuda quando precisavam, e a forneciam sempre que conseguiam. A meu ver, esse é um ponto relevante para as práticas de sala de aula, dado que descentraliza o papel do professor. Nesta pesquisa, os futuros professores não ficaram presos a mim ou ao grupo que criou a avaliação, todos participaram e se ajudaram.

Prensky (2010) defende um modelo de ensino participativo, em que todos ensinam e aprendem. Concordo com o posicionamento do teórico e, a partir da pesquisa que realizei, posso afirmar que os futuros professores aprendem mais e melhor quando constroem algo juntos, quando percebem que são capazes de produzir algo e, interagir utilizando a língua-alvo, seja por meio de postagens escritas ou áudios. Isso fez com que alguns participantes se sentissem mais confiantes, o que colaborou muito para o processo de ensino-avaliaçãoaprendizagem.

Sobre as reflexões acerca da construção da avaliação, o ponto mais difícil que o grupo teve foi com relação aos critérios. O início da apresentação do grupo (Nasus, Deby e Evelyn) foi para explicar porque eles trocaram os critérios, porque consideraram que não deveriam avaliar a pronúncia dos colegas. A partir da justificativa de Nasus, da troca do critério de pronúncia pelo de engajamento, noto que seu intuito (ou o intuito do grupo) foi colaborar para que os participantes não se sentissem prejudicados na avaliação. Para o futuro professor, aprender uma língua não significa falar sem sotaque, mas, sim, ser compreendido, se comunicar.

Essa concepção de língua como interação é relevante para a constituição dos futuros professores, pois não se avalia estrutura somente; ensinar uma língua vai além de regras ou de seguir modelos. Nessa linha de pensamento, concordo com Bakhtin (1981, p. 123), quando argumenta que a "interação verbal constitui assim a realidade fundamental da língua”. A língua, nessa perspectiva, seria a verdadeira natureza da linguagem. Dessa forma, para estabelecer relações no 
âmbito de uma determinada sociedade, o indivíduo interage em seu meio social por intermédio da linguagem, sendo desse modo constituído por ela. A seguir, apresento alguns excertos sobre a questão da dificuldade de seguirem os critérios estabelecidos com o grupo:

Nós tivemos esse medo de: não vamos dar nota, essa nota pro fulano, mas a gente vai prejudicar eles. Tenho medo, entendeu ou você (--) ai a gente pensou: vamos dar nota pra todo mundo? (EVELYN, discussão da avaliação WhatsApp)

E quarto [critério] era pra ser a pronúncia, só que o que? A pronúncia, eu achei que seria um pouquinho mais pesado, porque o objetivo é você ser entendido e não você falar bonito, certo. Ai, então, a gente, eu conversei com as meninas aqui e elas também concordaram da gente substituir o critério de pronunciação pelo critério de engajamento, assim, o interesse né, a colaboração de vocês para com a gente, né, nosso grupo né, a resposta de vocês. $\mathrm{E}$ isso eu achei sensacional (NASUS, discussão da avaliação WhatsApp).

Quando propus aos futuros professores a construção das avaliações, expliquei que precisariam de critérios de avaliação relacionados com os objetivos de aprendizagem. Em sala de aula, fizemos atividades para que aprendessem a construir os critérios e compreendessem sua relevância para a avaliação.

Assim, quando os futuros professores iniciaram a construção dos critérios, eu não quis interferir porque queria que eles passassem pela experiência e fiquei com receio de influenciar e não possibilitar que fizessem por eles mesmos. Eu discuti com eles quando precisavam de auxílio e apenas isso.

Sobre essa questão, McMillan (2010) defende a necessidade de se criar critérios claros de avaliação, para que não haja receio ou dúvidas no momento de fornecer uma nota ao trabalho. Sobre esse ponto considero que os critérios de avaliação fornecem uma transparência ao trabalho, desde que sejam públicos e que os alunos estejam cientes deles. McMillan (2010, p. 54), sobre a essencialidade de disponibilizar os critérios, argumenta ainda que "os alunos são mais capazes de ver que o conhecimento está sob seu controle e terão expectativas positivas sobre aprendizagem futura”.

Eu acredito que essa dificuldade que o grupo teve em seguir os critérios, em mudar um critério com receio de magoar os colegas, pode ter ocorrido por não ter ficado claro para eles o porquê precisamos de critérios. Em sala de aula, 
antes de construírem as avaliações, eu deveria ter trabalhado mais essa questão, enfatizei muito a questão de como construir critérios e talvez tenha desmerecido a questão de porquê construí-los.

Consequentemente, quando fomos discutir as avaliações construídas, percebi o quanto foi difícil para eles fornecerem uma nota, coavaliar os colegas foi algo muito complexo para essa turma. Por essa razão, discutimos novamente a relevância de se ter critérios de avaliação claros, de discutir esses critérios com os alunos, para que não existam problemas no momento de avaliar.

Ressalto que discutimos bastante em sala de aula a necessidade de se dar uma nota, um número, a uma avaliação. Acredito que, quando o foco da avaliação é colaborar para com a aprendizagem, essas notas não têm relevância. As avaliações podem ter formatos diversos, tais como escrita de diários, diálogos escritos e orais, nos quais é possível fornecer feedback sobre os pontos fortes e os aspectos a serem melhorados, com base nos critérios estabelecidos; esses fatores podem ser tão ou mais eficientes que a nota propriamente dita. Contudo, como esses professores em formação terão a necessidade de lidar com notas quando estiverem em serviço, considerei profícuo que eles também tivessem essa experiência para que pudéssemos refletir sobre ela.

O grupo que escolheu o aplicativo WhatsApp teve certo atrito entre os membros. Evelyn quis ser bastante criteriosa e Nasus e Deby pareceram não concordar com o posicionamento dela; os excertos de Nasus revelam o quanto essa questão de seguir estritamente os critérios o incomodou. Evelyn tentou manter os critérios preestabelecidos no momento de avaliar. Ela compreendeu que, se os colegas sabiam os critérios e se esforçaram por alcançá-los, seria injusto não levá-los em consideração.

A dificuldade em se fornecer uma nota também pode ser vista na modalização apreciativa de Amélie, quando ela afirma que "é muito difícil ser justo”. Como ser justo para avaliar? Como não punir o aluno? Todos esses questionamentos acerca da coavaliação foram feitos pelos futuros professores nas aulas. Aqui a avaliação parece ser compreendida como uma forma de poder, ter um aspecto punitivo, e não como um instrumento que poderia contribuir para a aprendizagem.

Em razão desses atritos para coavaliar, alguns participantes mudaram os critérios de avaliação e outros me enviaram várias mensagens inbox afirmando seu receio. "É, a distribuição de notas, avaliar o que eles escreveram, acho que 
essa foi uma parte que foi bem difícil, assim, não foi tão fácil” (Wonder Woman); "Não é aquela coisa, ele tentou fazer, mas não tá certo, será que eu considero? Você viu que tem uma lógica, mas tava errado, de acordo com os critérios" (Juliana).

Segundo Felice (2011) a coavaliação é um tipo de avaliação que demanda alguns cuidados, dado que há elementos como: receio de prejudicar os colegas, ser injusto com a nota atribuída. Todos esses elementos precisam e foram levados em consideração no momento de solicitar que os futuros professores avaliassem os colegas.

Nas discussões em sala, Maria afirmou que seria muito mais fácil avaliar uma sala de aula de ensino regular do que avaliar os colegas, os quais ela considera estar no mesmo nível de conhecimento. É possível notar que a coavaliação é algo complexo para os participantes. Segundo Santos (2011), a coavaliação é um momento em que é possível colaborar com a aprendizagem dos colegas, por meio da avaliação do desempenho dos alunos frente à determinada atividade, nesse caso específico, avaliações em ambiente online. Para o autor,

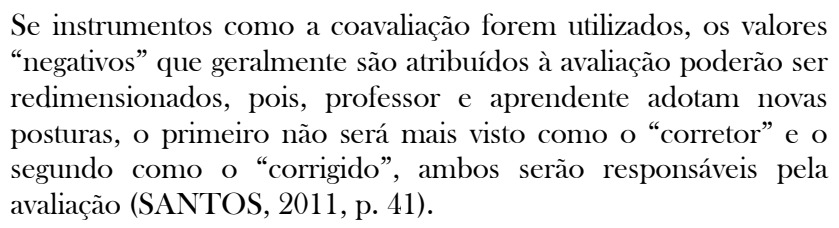

Considero pertinente afirmar que a coavaliação faz parte da avaliação formativa, e que inserir essas discussões em um curso de formação de professores pode trazer muitas reflexões para que repensem suas representações do que seja avaliar. Felice (2011, p. 590) argumenta que

\begin{abstract}
Seria importante enfatizar que essa avaliação dos pares visa a fazer com que cada um tenha um novo olhar sobre o ato de avaliar. É importante fazê-los perceber que avaliar tem relação com o desenvolvimento da crítica construtiva, visando à percepção do progresso pelos alunos durante a aquisição dos conhecimentos e que deve ser parte da formação do professor aprender a avaliar.
\end{abstract}

Apesar do receio de fornecer nota por parte da maioria dos futuros professores, eles compreenderam que os critérios de avaliação colaboram para ajudar a ser justo, conforme Deby afirma quando muda seu papel social de aluna 
para o de professora: "nós não pensamos nisso não, de dar zero, nós pensamos nos critérios de avaliação que foram passados”.

A partir da construção da avaliação e das discussões em sala, considero que houve contribuição para a formação inicial dos professores no que se refere às suas futuras práticas pedagógicas. Eles entenderam que avaliar a aprendizagem da língua não significa avaliar estrutura, que é preciso observar o que os alunos conseguem fazer e não avaliá-los por seus erros. Entretanto, houve dificuldade em se seguir os critérios estabelecidos, seja por receio de ser injusto, seja por outras razões, o que revela o quanto avaliar é algo subjetivo e complexo. Por mais que existam critérios, há outros fatores envolvidos.

Cizek (2010) e Abedi (2010) argumentam que, para que a avaliação formativa tenha espaço e seja disseminada no ambiente acadêmico, é preciso que seja incorporada nos cursos de formação de professores, e nos cursos de professores em serviço. Os excertos selecionados revelam uma preocupação com uma avaliação justa, isso porque o conceito de avaliação formativa foi discutido em sala de sala; talvez, se não houvesse discussão e reflexão sobre a temática, possivelmente o grupo não se atentaria para esse fator.

Todos esses fatores me fazem considerar que é preciso reforçar a questão da necessidade de propor objetivos de aprendizagem claros e relacioná-los aos critérios de avaliação. Assim como é preciso discutir com os alunos porque precisamos de critérios. Como professora formadora, acredito que deveria ser necessário explorar mais esses aspectos em sala de aula, para que os futuros professores refletissem sobre eles e não sentissem a dificuldade que tiveram em avaliar os colegas.

\section{CONCLUSÃO}

Neste artigo, que investigou a integração da tecnologia móvel WhatsApp para avaliação da aprendizagem em uma disciplina de língua inglesa em um curso de licenciatura, pude notar o comprometimento dos professores em formação em todo o processo, desde pensar a atividade à avaliação dos colegas. Todos esses fatores colaboraram em sua formação docente.

Os alunos do quinto período do curso de Letras que participaram desta pesquisa puderem refletir sobre o que é ser professor, sobre ser justo (ou não) no momento de avaliar, e seus olhares, provavelmente, não serão mais os mesmos. Percebo isso agora, pois, depois que finalizamos a disciplina e eles finalizaram o 
curso, os vejo preocupados com suas práticas pedagógicas, buscando formas de ensinar que não sejam tradicionais.

Construir uma avaliação utilizando tecnologias digitais, e avaliar os colegas a partir dos critérios selecionados pelo grupo, não foram tarefas fáceis ou tranquilas para a turma do quinto período de Letras. Nas discussões que tivemos em sala de aula sobre as avaliações, e que foram gravadas, os professores em formação inicial discutiram e descobriram que ser professor não é tão simples quanto parece.

O fato de eu ter pedido que fornecessem uma nota para os colegas deixou o processo complexo para alguns, como o grupo que utilizou o aplicativo Whats App, cuja saída foi mudar os critérios de avaliação, pois eles sentiram que iriam prejudicar os colegas com os critérios anteriormente selecionados. Em sala de aula, no momento de discutir sobre a avaliação, conversamos sobre a mudança nos critérios, uma vez que mudar os critérios depois de eles terem sido estabelecidos em comum acordo com os alunos não é adequado. Os participantes da pesquisa compreenderam a relevância de se manter o que foi estabelecido com os alunos, o que contribuiu para a formação docente.

De acordo com Kukulska-Hulme (2015, p. 287) "mídias digitais e móveis estão mudando o uso da linguagem”. Em relação à avaliação por meio das tecnologias móveis, parece ter ficado evidente que, quanto mais o aluno conhece e utiliza a tecnologia em seu cotidiano, menor será a dificuldade quando o uso se estender para o ambiente acadêmico.

Assim, por meio da experiência que tivemos, considero que os futuros professores tenham aprendido lições valiosas, visto que eles compreenderam a relevância de construir critérios claros de avaliação; compreenderam que as tecnologias digitais vieram para ficar e, desse modo, o melhor a fazer seria aproveitar todas as suas possibilidades.

\section{REFERENNCIAS}

ABEDI, Jamal. Research and Recommendations for Formative Assessments with English language learners. In: ANDRADE, Heidi; CIZEK, Gregory. (Eds.). Handbook of Formative Assessment. New York: Routledge. 2010. 
ANDRÉ, Marli Eliza Dalmazo Afonso. [1995]. Etnografia da Prática Escolar. 15 ed. Campinas, SP: Papirus, 2008.

BAKHTIN, Michail. (VOLOCHINOV). Marxismo e filosofia da linguagem. São Paulo: Hucitec. 1981.

BAX, Stephen. Normalisation revisited: the effective use of technology in language education. International Journal of Computer-Assisted Language Learning and Teaching. v.1(2): 1-15. 2011. Disponível em: <https://doi.org/10.4018/ijcallt.2011040101>. Acesso em 15/10/2019.

BOHN, Hilário. Ensino e aprendizagem de línguas: os atores da sala de aula e a necessidade de rupturas. In: MOITA LOPES, Luiz, Paulo. (Org.) Linguística aplicada na modernidade recente: festschrift para Antonieta Celani. 1. Ed, São Paulo: Parábola, p. 79-98. 2013.

BRAGA, Junia de Carvalho Fidelis; SILVA, Márcia Aparecida. Aprendizagem móvel e formação de professores de língua inglesa: presenças social, cognitiva e instrucional em interações via WhatsApp. In: ROCHA, Claudia Hilsdorf; EL KADRI, Michele Sales; WINDLE, Joel Austin. (Org.). Diálogos sobre tecnologia educacional: educação linguística, mobilidade e práticas translíngues. São Paulo: Pontes Editores. p. 163-190. 2017.

CIZEK, Gregory. An introduction to formative assessment: History, characteristics, and challenges. In: ANDRADE, Heidi; CIZEK, Gregory. (Eds.). Handbook of formative assessment New York: Routledge, p. 3-17. 2010.

COSTA, Giselda da Silva. Mobile learning: explorando potencialidades com o uso do celular no ensino - aprendizagem de língua inglesa como língua estrangeira com alunos da escola pública. Recife, PE. Tese de doutorado. Universidade Federal de Pernambuco, Letras, 182f. 2013.

DENZIN, Norman, K; LINCOLN, Yvonna, S. O planejamento da pesquisa qualitativa. Porto Alegre: Editora Artmed, 2. Ed, 2006.

GOMES, Luiz. Carlos. Falar e ouvir pela mediação das tecnologias digitais: o gênero exposição oral para o aprimoramento dos Multiletramentos dos professores de inglês da rede pública na Modalidade a distância. Belo Horizonte, MG. Dissertação de Mestrado, Universidade Federal de Minas Gerais. 165 f. 2015. 
FARIA, Helen Oliveira. A integração de prática educacionais e sociais na sala de aula de língua inglesa via gêneros digitais orais. Belo Horizonte, MG. Tese de doutorado. Universidade Federal de Minas Gerais. 240f. 2016.

FELICE, Maria. Inês. Vasconcelos. Qual o lugar da avaliação da aprendizagem na formação do Professor de línguas? In: Anais do XIII Simpósio Nacional de Letras e Linguística/ III Simpósio Internacional de Letras e Linguística. Universidade Federal de Uberlândia. Uberlândia, MG. 2011. Disponível em: $\langle$ http://www.ileel.ufu.br/anaisdosilel/pt/arquivos/silel2011/2942.pdf $>$. Acesso em $\underline{15 / 10 / 2019 .}$

FIUZA, Ana Cristina Borges. Histórias de formação de professores de língua espanhola: caminhos formais e não formais. Uberlândia, MG. Dissertação de Mestrado, Universidade Federal de Uberlândia, 111f. 2013.

LIMA, Samuel Carvalho. Ensino de língua mediado por computador: um estudo das propostas de atividades online para o ensino da compreensão e produção oral em língua inglesa. Fortaleza, CE. Tese de doutorado. Universidade Federal do Ceará. 139f. 2012.

MCMILLAN, James. The practical implications of Education aims and contexts for Formative Assessment. In: : ANDRADE, Heidi; CIZEK, Gregory. (Eds.). Handbook of Formative Assessment. New York: Routledge. p. 41-58. 2010.

MORAN, José. Educação híbrida: um conceito-chave para a educação, hoje. In: BACICH. Lilian; NETO. Adolfo Tanzi; TREVISANI, Fernando de Mello. Ensino híbrido: personalização e tecnologia na educação. Porto Alegre: Penso, p. 27-46. 2015.

KUKULSKA-HULME, Agnes. 2015. Language as a Bridge Connecting Formal and Informal Language Learning Through Mobile Devices. In: WONG, LungHsiang; MILRAD, Marcelo; SPECHT, Marcus. (Eds). Seamless Learning in the Age of Mobile Connectivity. London: Springerp, p. 281-294. 2015. Disponível em: 〈https://doi.org/10.1007/978-981-287-113-8 14〉. Acesso em 15/10/2019.

SANTOS, Vera Lucia Pontes; PEREIRA, Jasete Maria Santos, MERCADO, Luíz Paulo Leopoldo. WhatsApp: um viés online como estratégia didática na formação profissional de docentes. ETD - Educação. Temática. Digital. Campinas, SP, v.18(1): 104-121. 2016. 
PAIVA, Vera Lucia Menezes. A linguagem dos emojis. In: Trabalhos em Linguística Aplicada. Campinas, n. 55(2): 379-399. 2016. Disponível em: https://periodicos.sbu.unicamp.br/ojs/index.php/tla/article/view/8647400. Acesso em 15/10/20.

PEGRUM, Mark; HUWITT, Christine; STRIEPE, Michelle. Learning how to take the tablet: How pre-service teachers use iPads to facilitate their learning. Australian Journal of Educational Technology, v.29(4). 2013. Disponível em 〈http://ascilite.org.au/ajet/submission/index.php/AJET/article/view/187>. Acesso em 15/07/2019.

PRENSKY, Mark. Teaching digital natives: partnering for real learning. Sage Publications. 2010.

RECUERO, Raquel. Discurso mediado por computador nas redes sociais. In: ARAÚJO. Júlio; LEFFA, Vilson. Redes sociais e ensino de línguas. São Paulo, Parábola Editorial, p. 17-32. 2016.

REN, Ying; WARSCHAUER, Mark; LIND, Sonja; JENNEWINE, Louise. Technology and English language teaching in Brazil. Uberlândia: Revista Letras \& Letras, v. 25: 235-254. 2009.

SANTOS, Edirnelis Morais. A coavaliação como instrumento formativo no ensino aprendizagem da produção escrita em português como língua estrangeira. Ciências \& Cognição, V. 16(3): 37-42. Disponível em: <http://www.cienciasecognicao.org〉. Acesso em 15/10/2019. 2011

SIEMENS, George. Uma teoria da aprendizagem para a idade digital. International journal of instructional technology and distant learning. 2004. Disponível em: <http://www.academia.edu/7573922/CONECTIVISMO_Uma_Teoria_de_Apr endizagem_para_a_Idade_Digital $>$. Acesso em 15/10/2019.

SILVA, Márcia. Aparecida. Integração de tecnologias digitais para avaliar a aprendizagem em contexto presencial. Tese (doutorado em Estudos Linguísticos) - Universidade Federal de Uberlândia, Uberlândia, 2018. Disponível em: <http://dx.doi.org/10.14393/ufu.te.2018.611>. Acesso em 15/10/2019.

SOUZA, Valeska Virgínia Soares; MARTINS, Antonio Carlos Soares; RACILAN, Marcos. O uso de tecnologias digitais na avaliação da aprendizagem. 
In: BRAGA, Junia Fidelis. (Org.). Integrando tecnologias no ensino de inglês nos anos finais do ensino fundamental. 1ed.São Paulo: Editora SM, p. 188-203. 2012.

TARAS, Madalena. Assessment for learning: understanding theory to improve practice. Journal of Further and Higher Education. 31(4):363-371. 2007. Disponível em: http://dx.doi.org/10.1080/03098770701625746. Acesso em $\underline{15 / 10 / 2019 .}$

, Madalena. Summative assessment: the missing link for formative Assessment. Journal of Further and Higher Education. 33(1):57-69. 2009. Disponível em: http://dx.doi.org/10.1080/03098770802638671. Acesso em $\underline{15 / 10 / 2019 .}$

WARSCHAUER, Mark. The paradoxical future of digital learning. Learning Inquiry. $\quad$ V. 1(1):41-49. $2007 . \quad$ Disponível em: 〈http://ink.springer.com/article/10.1007/s11519-007-0001-5/fulltext.html〉. Acesso em 15/05/2020.

Mark. Learning in the cloud: how (and why) to transform schools with digital media. Teachers College Press New York: NY. 2011.

WILIAM, Dylan. 2010. An integrative summary of the research literature and implications for a new theory of formative assessment. In: ANDRADE. Heidi; CIZEK. Gregory. (Eds.). Handbook of Formative Assessment. New York: Routledge. 2010.

Recebido em 16 de setembro de 2020 Aprovado em 28 de outubro de 2020 